\title{
Outcome of Infants with Hypoxic-Ischemic Encephalopathy Treated by Whole Body Cooling and Magnesium Sulfate
}

\author{
Safwat M. Abdel-Aziz ${ }^{1}$ Mohamed Sabry M. Abdel Rahman ${ }^{1} \quad$ Asmaa H. Shoreit ${ }^{1} \quad$ Moustafa Ez El Din ${ }^{2}$ () \\ Enas A. Hamed ${ }^{3}$ Eman Fathalla Gad ${ }^{1}$
}

${ }^{1}$ Department of Pediatrics and Neonatology, Assiut University Children's Hospital, Assiut, Egypt

2 Department of Radiology, Faculty of Medicine, Assiut University, Assiut, Egypt

${ }^{3}$ Department of Medical Physiology, Faculty of Medicine, Assiut University, Assiut, Egypt

J Child Sci 2021;11:e280-e286.

\begin{abstract}
Address for correspondence Enas Ahmad Hamed, MD, PhD, Department of Medical Physiology, Faculty of Medicine, Assiut University, Assiut, P.O. Box 71516, Egypt (e-mail: eah3a2010@aun.edu.eg).
\end{abstract}

\begin{abstract}
Keywords

- hypoxic-ischemic encephalopathy

- magnesium sulfate

- neuroprotective

- therapeutic hypothermia

Therapeutic hypothermia (TH) either by selective head cooling or whole-body cooling decreases brain damage and provide neuroprotection and reduced mortality rate in cases of moderate-to-severe hypoxia-ischemia encephalopathy (HIE) of newborns, especially if started at first 6 hours after birth. Also, management with adjuvant therapies like magnesium sulfate (MS) provides more neuroprotection. The interventional randomized controlled research aimed to assess short-term actions of TH as sole therapy and in combination with MS as a neuroprotective agent for the treatment of HIE newborn infants. A total of 36 full-terms and near-term infants delivered at Assiut University Children's Hospital and fulfilled HIE criteria were enrolled. They were divided equally into three groups; Group $1(n=12)$ received whole body cooling during first 6 hours of life as a sole therapy; Group $2(n=12)$ received whole body cooling in addition to MS as adjuvant therapy; Group $3(n=12)$ received supportive intensive care measures as a control. TH plus MS group (group 2 ) had a significantly good short-term outcomes as short period of respiratory support and mechanical ventilation ( $p$-value $=0.001$ ), less in incidence of convulsion ( $p$-value $=0.001$ ) and early in feeding initiation ( $p$-value $=0.009)$, compared with other groups managed by TH (group 1 ) or by supportive treatment (group 3). In conclusion, whole body cooling in addition to MS as adjunctive therapy for the treatment of HIE neonates is safe therapy that improves short-term outcome both clinically and radiologically.
\end{abstract}

\section{Introduction}

Hypoxic-ischemic encephalopathy (HIE) is an acquired syndrome manifested by a clinical, laboratory, and radiological evidence of acute brain injury. ${ }^{1}$ Perinatal asphyxia affects two out of every 1,000 live births in wealthy countries, but it affects

received

July 1,2021

accepted after revision

August 30, 2021
DOI https://doi.org/

ISSN 2474-5871. 10.1055/s-0041-1736562.
10 times more people in developing countries when maternal and newborn care is inadequate. 15 to $20 \%$ of asphyxiated neonates will die during neonatal duration, and roughly $25 \%$ of survivors will have long-term neurological impairments. ${ }^{2}$

HIE is accompanied by two phases of pathologic events, primary and secondary energy failure. A decrease in cerebral

\section{(c) 2021. The Author(s).}

This is an open access article published by Thieme under the terms of the Creative Commons Attribution License, permitting unrestricted use, distribution, and reproduction so long as the original work is properly cited. (https://creativecommons.org/licenses/by/4.0/)

Georg Thieme Verlag KG, Rüdigerstraße 14, 70469 Stuttgart, Germany 
blood flow and oxygen substrate, as well as significant tissue acidity, characterize primary energy failure. ${ }^{3}$ Secondary energy failure includes several pathophysiologic actions as summation of excitatory brain neurotransmitters, oxidative stress, inflammation, apoptosis, changed growth factors, and protein formation. ${ }^{4}$ There is a latent phase between primary and secondary energy failure, which corresponds to a therapeutic window of roughly 6 hours during which neuroprotective therapy should be started. ${ }^{5}$

Hypothermia of the brain is an example of a neuroprotective treatment that influences several processes in the events that lead to brain injury. In newborns, a slight drop in brain temperature $\left(1\right.$ to $\left.6^{\circ} \mathrm{C}\right)$ is linked to better cerebral energy maintenance during and immediately after birth ischemia. Other neuroprotective actions of brain hypothermia include stabilization of protein formation, decline of free oxygen radicals, and control of microglial activation and cytokine formation, as well as attenuation of excitatory neurotransmitter release and apoptosis. ${ }^{6}$ Other neuroprotective therapies should be added to increase the benefits of therapeutic hypothermia $(\mathrm{TH})$ and to minimize neonatal brain injury and make more neuroprotection; many researches support the safety and potency of magnesium sulfate (MS) as an adjuvant therapy to $\mathrm{TH}^{7-9}$

Postnatally after birth asphyxia, infusion of magnesium sulfate $(250 \mathrm{mg} / \mathrm{kg}$ per day for 3 days $)$ in combination with dopamine (5 ug/ $/ \mathrm{kg}$ per minute) associated with a good neurodevelopmental outcome as it acts as non-competitive antagonization effect at $\mathrm{N}$-methyl D-aspartate (NAMDA) glutamate receptors, stabilization of many critical enzymatic reactions, plasma membrane and anticonvulsant actions. Combination therapies as MS plus TH provide more synergistic neuroprotective effects and improve outcomes. ${ }^{10-12}$

Thus, the present research aimed to assess the neuroprotective actions of $\mathrm{TH}$ in addition to MS as adjunctive therapy in management of neonates with HIE.

\section{Methods}

The interventional randomized controlled research was made on 36 neonates delivered at the neonatal intensive care unit (NICU) of Assiut University Children's hospital, fulfilling the physiological and neurological inclusion criteria during period from January 2019 to June 2020. Physiologic criteria were infants $\geq 36$ weeks gestation administered to NICU with at least one of the followings: Apgar score at 5 minutes following birth $\leq 5$; continued requirement for resuscitation as mask or endotracheal ventilation, at 10 minutes following birth; acidosis within 60 minutes of birth with an arterial, umbilical cord, or capillary $\mathrm{pH}<7.1$ or base deficit $\geq 16 \mathrm{mmol} / \mathrm{L}$; manifestations of fetal distress before delivery (as meconium-stained amniotic fluid or tachycardia $>160 / \mathrm{bpm}$ or bradycardia $<100 / \mathrm{bpm}$ ). Neurological criteria were changes of consciousness (lethargy, stupor, or coma) and at least one of the following: clinical seizures; abnormal pupillary reflexes; abnormal oculomotor reflex; absent or weak suckling; absent or weak Moro reflex, and hypertonia. Excluded from the study were preterm infants, infants with congenital anomalies, and infants of mothers received medications that caused neonatal depression as phenobarbitone or pethidine.

\section{Study Population and Sampling Size}

All newborn that admitted to NICU of Assiut University Children's Hospital, Assiut, Egypt with moderate to severe HIE graded as Sarnat modified score system ${ }^{13}$ during the research period were included. The patients were separated into two subgroups before randomly assigning them to moderate and severe HIE, then each group divided into three groups. The researchers randomly assigned the neonates into three groups according to severity of HIE, priority of admission and available places in NICU by utilizing random number tables generated by computer according to the inclusion and exclusion characteristics. Not any of the NICU's nurses or the attending neonatologists was aware of this randomization.

\section{Data Collection Tools}

Complete maternal, obstetric, and neonatal histories, full clinical examination including neurological examination, full laboratory assessment including complete blood count, serum urea, creatinine, magnesium, calcium and potassium and blood glucose were done.

\section{Patients}

Group $1(n=12)$ included HIE neonates treated by whole body cooling within 6 hours after birth for 72 hours as a sole therapy. Group $2(n=12)$ included HIE neonates treated by whole body cooling within 6 hours after birth for 72 hours in addition to a prophylactic dose of intravenous MS (250 $\mathrm{mg} / \mathrm{kg}$ ) with dopamine $(5 \mu \mathrm{g} / \mathrm{kg} / \mathrm{min})$ over 1 hour for 3 days. Group $3(n=12)$ included HIE neonates received supportive treatment and served as a control. In the control group, the traditional treatment (supportive measures) only was used for management of HIE cases due to lack of capabilities, availability of places of newborn, and cooling device (relying solely on gel mattresses and passive cooling) in our NICU. Also, lack of nursing assistant staff in close monitoring and follow-up of these cases led to use of traditional treatment for management of these cases in spite of the beneficial effect of TH. Cooling was initiated within 6 hours after birth and continued for 72 hours, and all newborns were closely monitored and treated in a standard manner with attention to maintenance of oxygen saturation, blood pressure, normal blood gases, fluid balance, and kidney functions, with management of seizure, hypoglycemia, and jaundice. The target temperature during cooling must be 33 to $34^{\circ} \mathrm{C}$ during hypothermic therapy and rewarming; the temperature was registered continuously, and the temperature was registered every hour. The aim was to get the target temperature by 1 hour of starting cooling. TH was begun with passive cooling first, but if the temperature did not drop below $35^{\circ} \mathrm{C}$ after 30 minutes, active cooling was used. The newborn was kept naked in an open incubator at room temperature with the radiant heater turned off, while active cooling was achieved by utilizing a cool mattress at a 
Table 1 Demographic features of the studied groups

\begin{tabular}{|l|l|l|l|l|l|}
\hline Parameters & Total $(\boldsymbol{n}=\mathbf{3 6})$ & $\begin{array}{l}\text { TH group } \\
(\boldsymbol{n}=\mathbf{1 2})\end{array}$ & $\begin{array}{l}\text { TH and MS group } \\
(\boldsymbol{n}=\mathbf{1 2})\end{array}$ & $\begin{array}{l}\text { Control group } \\
(\boldsymbol{n}=\mathbf{1 2})\end{array}$ & $p$-Value \\
\hline Gender & $22(61.11 \%)$ & $6(50.0 \%)$ & $7(58.3 \%)$ & $9(75.0 \%)$ & 0.441 \\
\hline Males & $14(38.89 \%)$ & $6(50.0 \%)$ & $5(41.7 \%)$ & $3(25.0 \%)$ & \\
\hline Females & $3.42 \pm 0.55$ & $3.31 \pm 0.54$ & $3.44 \pm 0.42$ & $3.52 \pm 0.70$ & 0.419 \\
\hline Birth weight (kg) & $38.31 \pm 1.66$ & $38.24 \pm 1.42$ & $38.60 \pm 1.76$ & $38.1 \pm 1.80$ & 0.207 \\
\hline Gestational age (weeks) & \multicolumn{5}{|l|}{} \\
\hline Mode of delivery & \multicolumn{7}{|l|}{} \\
\hline Normal vaginal delivery & $16(44.44 \%)$ & $5(41.7 \%)$ & $6(50.0 \%)$ & $5(41.7 \%)$ & 0.939 \\
\hline Cesarean section & $11(30.56 \%)$ & $3(25.0 \%)$ & $4(33.3 \%)$ & $4(33.3 \%)$ & 0.913 \\
\hline Forceps delivery & $3(8.33 \%)$ & $2(16.7 \%)$ & - & $1(8.3 \%)$ & 0.998 \\
\hline Ventose delivery & $4(11.11 \%)$ & $1(8.3 \%)$ & $1(8.3 \%)$ & $2(16.7 \%)$ & 0.778 \\
\hline Assisted breech & $2(5.56 \%)$ & $1(8.3 \%)$ & $1(8.3 \%)$ & - & 0.479 \\
\hline
\end{tabular}

Abbreviations: MS, magnesium sulfate; $\mathrm{TH}$, therapeutic hypothermia.

Note: Comparison between groups was made using Pearson Chi-Square test.

temperature of around $10^{\circ} \mathrm{C}$. If the temperature of the newborn drops below $33^{\circ} \mathrm{C}$, the cooling mattress or packs are withdrawn. If that was not enough, the radiant heater is turned on to the lowest setting until the temperature reaches $33^{\circ} \mathrm{C}^{14}$ Rewarming to a temperature of $37^{\circ} \mathrm{C}$ was done slowly after 72 hours of $\mathrm{TH}$.

This was accomplished by regulating the radiant heater's temperature to raise the patient's temperature by no more than $0.5^{\circ} \mathrm{C}$ every hour. ${ }^{15}$ Assessment of cases was done by both clinical and radiological evaluation. Clinical evaluation was made using Thompson and Sarnat scoring systems. Magnetic resonance imaging (MRI) ${ }^{16}$ scans were used to assess radiological evaluation; the babies were examined when they were stable to be carried securely to MRI scanner. ${ }^{17}$

The incidence of convulsion and neurological status, the period of mechanical ventilation and respiratory support, neurological finding in MRI, and the time of starting feeding were recorded.

\section{Ethical Issues}

Research was approved by Local Ethical Committee Institutional Review Board (IRB) of Assiut University Hospital, Assiut, Egypt (IRB: 17200592, December 26, 2018) which was according to Declaration of Helsinki. Informed written consent was got from mothers or guaranteed of every participant before inclusion and after explaining research aim to them at admission time.

\section{Statistical Analysis}

Descriptive statistical analysis was made by IBM SPSS statistics software version 25; SPSS inc. for Windows Microsoft. Shapiro - Wilk test was utilized to evaluate normal value distribution. Data were collected, checked, coded, and entered. Statistical methods included descriptive analysis like mean, standard deviation, number and Pearson Chi-square test percentage. Significance between groups was done using Chi-Square test for categorized data and one-way ANOVA test then by post hoc least significant difference for parametric variables. $p<0.05$ was considered statistically significant.

\section{Results}

- Table 1 showed the demographic features between the studied groups. Where six (50\%) of the cases were males and also six (50\%) were females in the neonates with hypothermia group and seven (58.3\%) males and five (41.7\%) females in hypothermia and MS group, while in control group nine (75\%) were males and three (25\%) were females with insignificant difference between groups $(p=0.441)$. Among hypothermia, hypothermia plus MS and control groups, there were insignificant difference between groups regarding birth weight $(3.31 \pm 0.54 \mathrm{~kg} ; 3.44 \pm 0.42 \mathrm{~kg}$, and $3.52 \pm 0.7 \mathrm{~kg}$, respectively, $p=0.419)$ and gestational age (38.24 \pm 1.42 ; $38.60 \pm 1.76$; and $38.1 \pm 1.8$ weeks, respectively; $p=0.207$ ). The modes of delivery for the hypothermia; hypothermia and MS and control groups were vaginal (41.7, 50.0, and $41.7 \%$, $p=0.939)$, CS $(25.0,33.3$, and $33.3 \%, p=0.913)$, forceps ( 16.7 , $0,8.3 \%, p=0.998)$, ventose $(8.3,8.3$, and $16.7 \%, p=0.778)$ and assisted breech $(8.3,8.3$, and $0 \%, p=0.479)$.

- Table 2 demonstrates the pregnancy-related risk factors of infants with HIE. There was statistically significant difference among the studied groups regarding pre-eclampsia, antepartum hemorrhage, and prolonged $2^{\text {nd }}$ stage of labor $(p=0.017, p=0.019, p=0.016$, respectively).

-Fig. 1 demonstrates the short-term outcomes and MRI findings among the studied groups. There were statistically significant differences in hypothermia and MS group versus hypothermia and control groups and in hypothermia group versus control group regarding duration of respiratory support $(p=0.023 ; p=0.001$, and $p=0.005$, respectively); frequency of convulsions ( $p=0.005 ; p=0.002$, and $p=0.002$, respectively); initiation of feeding ( $p=0.005 ; p=0.001$, and $p=0.008$, respectively); antiepileptic drugs at discharge $(p=0.001$; $p=0.007$, and $p=0.031$, respectively). MRI finding in 
Table 2 Pregnancy-related risk factors of infants with hypoxic ischemic encephalopathy

\begin{tabular}{|l|l|l|l|l|l|}
\hline Pregnancy risk factors & Total $(\boldsymbol{n}=\mathbf{3 6})$ & $\begin{array}{l}\text { TH group } \\
(\boldsymbol{n}=\mathbf{1 2})\end{array}$ & $\begin{array}{l}\text { TH and MS group } \\
(\boldsymbol{n}=\mathbf{1 2})\end{array}$ & $\begin{array}{l}\text { Control group } \\
(\boldsymbol{n}=\mathbf{1 2})\end{array}$ & $p$-Value \\
\hline Eclampsia & $4(11.11 \%)$ & $1(8.3 \%)$ & $1(8.3 \%)$ & $2(16.7 \%)$ & 0.778 \\
\hline Pre-eclampsia & $8(22.22 \%)$ & $4(33.3 \%)$ & $3(25.0 \%)$ & $1(8.3 \%)$ & 0.017 \\
\hline Previous stillbirth & $2(5.56 \%)$ & $1(8.3 \%)$ & $1(8.3 \%)$ & - & - \\
\hline $\begin{array}{l}\text { Cord prolapse and } \\
\text { placental insufficiency }\end{array}$ & $4(11.11 \%)$ & $1(8.3 \%)$ & $1(8.3 \%)$ & $2(16.7 \%)$ & 0.778 \\
\hline Antepartum hemorrhage & $5(13.89 \%)$ & $2(16.7 \%)$ & $1(8.3 \%)$ & $2(16.7 \%)$ & 0.019 \\
\hline $\begin{array}{l}\text { Premature rupture of } \\
\text { membrane. }\end{array}$ & $5(13.89 \%)$ & $2(16.7 \%)$ & $2(16.7 \%)$ & $1(8.3 \%)$ & 0.819 \\
\hline Prolonged 2nd stage of labor & $9(25.0 \%)$ & $2(16.7 \%)$ & $3(25.0 \%)$ & $4(33.3 \%)$ & 0.016 \\
\hline
\end{tabular}

Abbreviations: MS, magnesium sulfate; TH, therapeutic hypothermia. Comparison between groups was made using Pearson Chi-Square test.

hypothermia group was normal in 11 cases (92.7\%) and gray and white matter lesion in one case (8.3\%); in hypothermia with MS group findings were normal in 11 cases (92.7\%) and cortical lesion in one case (8.3\%), in the control group it was normal in 10 cases $(83.4 \%)$, cortical lesion in one case $(8.3 \%)$ and gray and white matter lesion in one case (8.3\%) with insignificant difference between different findings (normal, cortical lesion and gray, and white matter lesion) in different groups ( $p=0.307, p=00.867$, and $p=0.819$, respectively).

\section{Discussion}

Hypothermia is a standard-of-care for babies suffering from HIE but the hypothermia does not provide complete neuroprotection, so adding a pharmacological agent may improve outcomes. MS is a good example of these agents which are used in neonates, producing neuroprotective effects. ${ }^{18}$ This prospective intervention research was designed to test short-term effect of whole body cooling alone and whole body cooling plus MS as a neuroprotective agent to infants with HIE admitted to NICU of Assiut University children's hospital and fulfilling the inclusion characteristics for the research.

In this study, there was an insignificant difference with regard to gender between the three studied groups. Meanwhile, the number of males ( $n=22,61.11 \%$ ) was exceeding that of females where six (50\%) of the cases were males and also six (50\%) were females in neonates with hypothermia group and seven (58.3\%) males and five (41.7\%) females in hypothermia and MS group, while in control group nine (75.0\%) were males and three (25.0\%) were females. A study conducted by Siegel et al, ${ }^{19}$ in Pakistan on 144 neonates with perinatal asphyxia had $68.8 \%$ of cases as males and $31.3 \%$ as females. This study reported that male sex adversely affected neonates outcome in cases with perinatal asphyxia. ${ }^{19}$ Cerebral ischemia stimulates both caspase-independent and caspase-dependent cell death pathways. Stroke-led to cell death in males is triggered by mitochondrial release of apoptosis-inducing substances which results in cell death that is not dependent on caspase.
Regarding the pregnancy-related risk factors of infants with HIE in total, nine (25.0\%) had prolonged second stage of labor, eight women (22.22\%) had pre-eclampsia, five (13.89\%) had an antepartum hemorrhage, five (13.89\%) had premature rupture of membranes, four $(11.11 \%)$ had cord prolapse and placental insufficiency, four women (11.11\%) had eclampsia, and two (5.56\%) had a previous stillbirth. Prolonged 2nd stage of labor, preeclampsia, and antepartum hemorrhage showed significant difference between various studied groups $(p=0.016, p=0.017$, and $p=0.019)$. Torbenson et $\mathrm{al}^{20}$ reported that prolonged second stage of labor and presence of meconium-stained amniotic fluid were risk factors for HIE development. In contrast to our results, a research conducted by Hashim et $\mathrm{al}^{21}$ stated that significantly higher risk was associated with prolonged rupture of membranes that is a risk factor for fetal sepsis and associated with deterioration in the fetal acid-base status. Also, Peebles et $a^{22}$ reported that moderate-to-heavy meconium-stained amniotic fluid, placental abruption, ruptured uterus, and delivery by cesarean-section were independent intrapartum risk factors for HIE in newborn. An intrapartum risk factor was found in $70.3 \%$ of HIE group versus $29.6 \%$ in non-HIE group.

According to the mode of delivery, our research revealed that there was no statistically significant difference between the different modes of delivery among different studied groups of HIE. Among all HIE group, most of the deliveries were normal vaginal delivery $(n=16,44.44 \%)$, then cesarean section $(n=11,30.56 \%)$, ventose delivery ( $n=4,11.11 \%)$, forceps delivery $(n=3,8.33 \%)$, and last assisted breech $(n=2,5.56 \%)$. In line with the results of this study, Hill ${ }^{23}$ and Badawi et $\mathrm{al}^{24}$ reported that the normal vaginal delivery is associated with HIE. Dongol et $\mathrm{al}^{25}$ reported that most vaginal deliveries are associated with perinatal and intrapartum asphyxia. In contrast, Seyal and Hanif ${ }^{26}$ reported that most of infants with birth asphyxia were born by cesarean section. This could be explained by either internal hospital protocols that support CS or utilization of CS as ultimate mode of delivery after failed trials of normal vaginal delivery. 
A

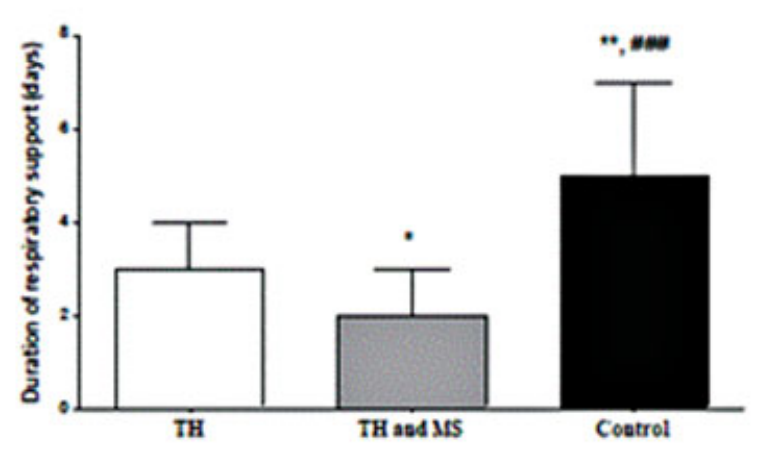

C

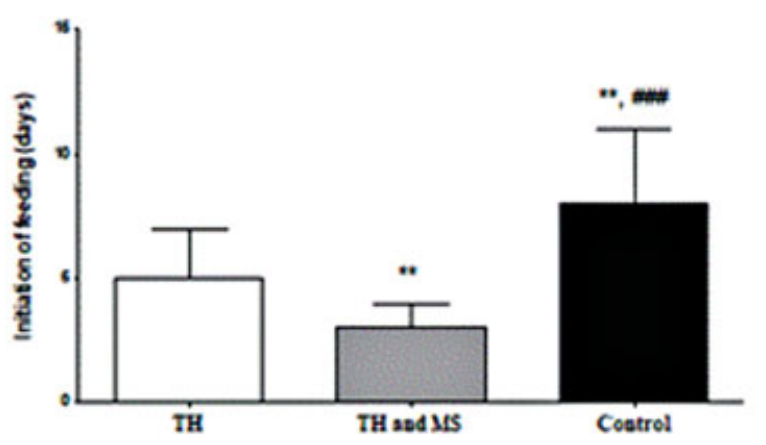

E

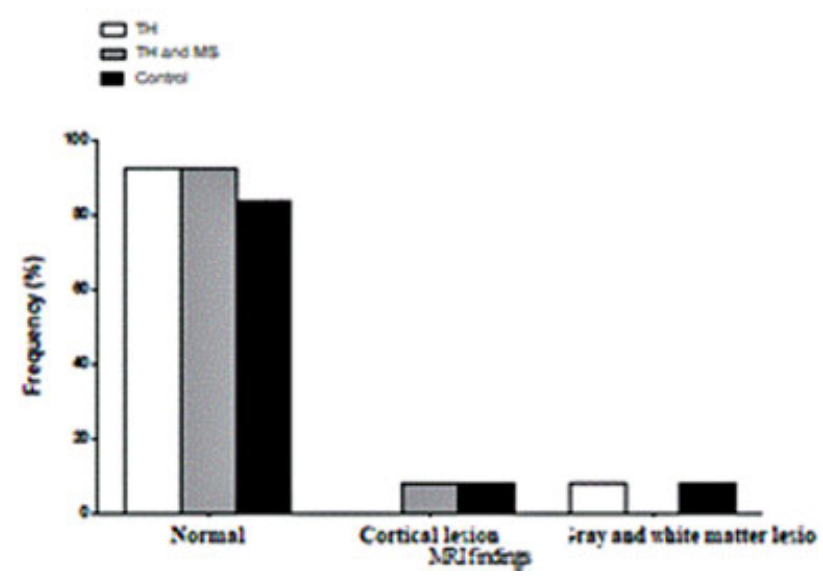

B

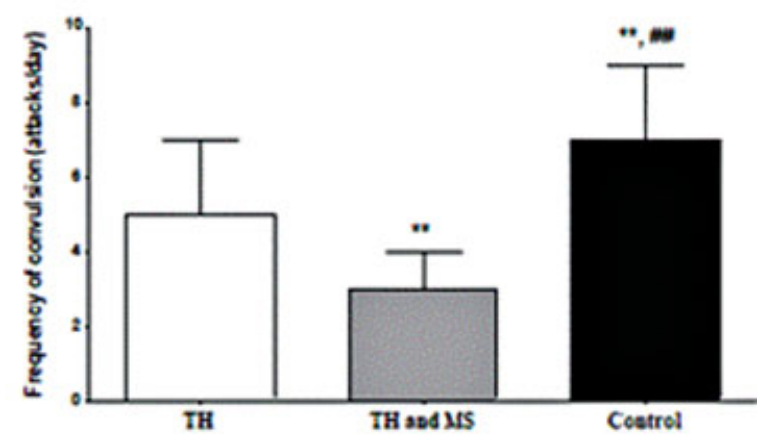

D

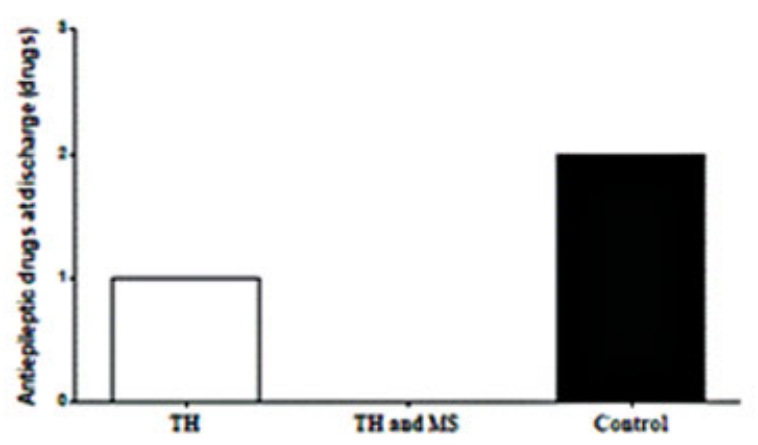

Fig. 1 Short-term outcomes among the studied groups. MS, magnesium sulfate; $\mathrm{TH}$, therapeutic hypothermia; ${ }^{*}$ Significance versus TH group; ${ }^{\#}$ Significance versus TH and MS group. ${ }^{*} p<0.05 ;{ }^{* *} p<0.010$, and ${ }^{* * *} p<0.0001$. A: Duration of respiratory support (days); B: Frequency of convulsion (attacks/day); C: Initiation of feeding (days); D: Antiepileptic drugs at discharge (drugs); e: Frequency of MRI findings (\%). Comparison between categorized data was made using Person Chi-Square test and using OneWay ANOVA test followed by LSD for parametric parameters.

According to the short-term outcomes among the studied groups, our results showed a significant statistical difference among three studied groups with regard to the incidence and frequency of clinical seizures ( $p=0.001)$, respiratory support duration $(p=0.001)$, and time of enteral feeding initiation $(p=0.009)$. Our results reveal that, the group that received hypothermia with MS had a shorter length of mechanical ventilation and respiratory support versus group that re- ceived hypothermia alone, which was likewise shorter than the control group. In addition, the time it took to start feeding was less in the group that received hypothermia with MS than in the group that received hypothermia. A meta-analysis of five studies of infants with HIE found that TH had a substantial influence on the incidence of clinically identifiable seizures. ${ }^{27,28}$ Sajid et al ${ }^{29}$ found that neurological outcomes at discharge were improved with the treatment of 
postnatal intravenous MS $(250 \mathrm{mg} / \mathrm{kg} /$ dose, 24 hours interval for three doses) in neonates with severe birth asphyxia when given early after birth. In line with the present study, Abate et $\mathrm{al}^{30}$ found that, TH decreased the mortality risk in neonates with moderate to severe HIE. Both selective head cooling and whole-body cooling methods were effective in decreasing mortality of HIE infants. Also, low-income countries benefit the most from therapy.

Lingam et $\mathrm{al}^{31}$ studied the neuroprotective effects of MS bolus and infusion over 48 hours $(180 \mathrm{mg} / \mathrm{kg}$ bolus then $8 \mathrm{mg} / \mathrm{kg} / \mathrm{h}$ infusion) and $\mathrm{TH}$ for 12 hours $\left(33.5^{\circ} \mathrm{C}\right)$ and $\mathrm{TH}$ only in piglets' model of term neonatal encephalopathy. They reported that in MS plus TH versus TH only, there were overall decreased cell death $(p=0.010)$ and increased oligodendrocytes $(p=0.002)$. Meanwhile, there were no improvement on amplitude integrated electroencephalography recovery $(p=0.084)$ or magnetic resonance spectroscopy (Lac/NAA; PCr/Pi; NTP/epp) ( $p>0.05$ ) at 48 hours. Prakash ${ }^{32}$ made a study on term asphyxiated infants that were received either MS infusion $(n=60)$ or placebo $(n=60)$ within 48 hours of life. MS infusion was administered at dose of $250 \mathrm{mg} / \mathrm{kg} /$ dose $(1 \mathrm{~mL} / \mathrm{kg} /$ dose in $20 \mathrm{~mL}$ of $5 \%$ dextrose solution) over 1 hour within 6 hours after birth, with two more doses repeated at intervals of 24 hours. The author reported that 25/36 infants in the magnesium group (69\%) and 27/33 controls (82\%) with moderate and severe HIE had clinical seizures during NICU admission. Among those with seizures, seizure control was achieved with single anticonvulsant in 24 infants (96\%) in MS group compared with 20 (74\%) in placebo $(p=0.020)$. Seizures got controlled early in MS group compared with placebo, 36.5 hours versus 55 hours $(p=0.020)$. At discharge, anticonvulsant was required for two infants in MS group and three in placebo group. Okonkwo and Okolo ${ }^{33}$ reported that postnatal administration of MS alone or combined with respiratory support improves survival of asphyxiated neonates and neonates with encephalopathy. Bhat et $\mathrm{al}^{10}$ found that postnatal MS treatment improved neurological outcomes at discharge for full-term neonates with severe perinatal asphyxia. Sreenivasa et $\mathrm{al}^{34}$ reported that early (within 6 hours) postnatal intravenous MS infusion is effective in improving short-term outcomes for infants with perinatal asphyxia.

MRI patterns of brain injury vary because of differences in brain maturity at the time of insult, severity, and duration of the insult. Aun et $\mathrm{al}^{35}$ reported that MRI imaging is considered a sensitive method in detecting various patterns of encephalopathy in newborns and used for early predictor of future development of neurological abnormalities in neonates with encephalopathy. Rutherford et al $^{36}$ stated that MRI is an excellent predictor of outcome following perinatal brain injury and can be used in interventional trials designed to decrease damage and enhance neurodevelopmental outcome. The results of this research showed the use of MS in addition to whole-body cooling associated with decline in cerebral damage seen on MRI which are characteristic of HIE. ${ }^{37}$ Therefore, out of 36 cases that had MRI scans in the present study, 32 cases (88.89\%) showed normal MRI in spite they had fulfilled the charac- teristics of hypoxic encephalopathy. Where in the hypothermia group, normal MRI was present in 11 cases (92.7\%) and gray and white matter lesion in one case (8.3\%). In hypothermia with MS group, normal MRI was present in 11 cases (92.7\%) and cortical lesion in one case (8.3\%). In the control group, normal MRI was present in 10 cases (83.4\%), cortical lesion in one case $(8.3 \%)$, and gray and white matter lesion in one case $(8.3 \%)$. This supports our theory that cooling, with or without prophylactic MS, may have reduced the degree of hypoxic brain injury. Cheong et $\mathrm{al}^{38}$ stated that brain injury on T1- and T2-weighted MRI decreased in hypothermia-treated newborns. Abnormal MRI are prognostic of long-term outcome in moderate to severe HIE regardless of hypothermia therapy.

\section{Limitations of the Study}

The study's neonatal sample was limited, separated into three groups, and the patients came from a single tertiary hospital. A high sample size is recommended.

\section{Conclusion}

Whole body cooling is a safe, effective, and inexpensive mode of intervention, which has become standard therapy for neonates with HIE and it is achievable, using simple and easily available cooling materials. Adding MS to cooling therapy for HIE significantly shortens the period of hospital stay, decreasing the incidence of convulsions and helps in early starting of feeding and decreasing the findings in MRI brain and uses of anticonvulsant therapy. Follow-up of HIE cases treated with TH is highly recommended to determine the long-term effects.

\section{Author's Contributions}

M.S.M.A.R. carried the study design, examined cases, and shared in writing of manuscript. A.H.S. selected the cases, did the validation, and coding, shared in writing manuscript. M.E.E.D. was involved in the selection of cases, MRI reading and interpretation and shared in writing manuscript and gathered references. E.A.H. did the validation, analysis of data and coding, shared in writing manuscript, reviewed and edited. S.M.A.-A. did the study design, conceptualization, writing manuscript, validation, and editing. All authors had read and approved manuscript for publication.

\section{Funding \\ None.}

Conflict of Interest

None declared.

\section{References}

1 Martinello K, Hart AR, Yap S, Mitra S, Robertson NJ. Management and investigation of neonatal encephalopathy: 2017 update. Arch Dis Child Fetal Neonatal Ed 2017;102(04): F346-F358 
2 Odd D, Heep A, Luyt K, Draycott T. Hypoxic-ischemic brain injury: planned delivery before intrapartum events. J Neonatal Perinatal Med 2017;10(04):347-353

3 Dixon BJ, Reis C, Ho WM, Tang J, Zhang JH. Neuroprotective strategies after neonatal hypoxic ischemic encephalopathy. Int J Mol Sci 2015;16(09):22368-22401

4 Arteaga O, Álvarez A, Revuelta M, Santaolalla F, Urtasun A, Hilario E. Role of antioxidants in neonatal hypoxic-ischemic brain injury: new therapeutic approaches. Int J Mol Sci 2017;18(02):265

5 Laptook AR, McDonald SA, Shankaran S, et al; Extended Hypothermia Follow-up Subcommittee of the National Institute of Child Health and Human Development Neonatal Research Network. Elevated temperature and 6- to 7-year outcome of neonatal encephalopathy. Ann Neurol 2013;73(04):520-528

6 Wassink G, Davidson JO, Dhillon SK, et al. Therapeutic hypothermia in neonatal hypoxic-ischemic encephalopathy. Curr Neurol Neurosci Rep 2019;19(02):2

7 Nonomura M, Harada S, Asada Y, et al. Combination therapy with erythropoietin, magnesium sulfate and hypothermia for hypoxicischemic encephalopathy: an open-label pilot study to assess the safety and feasibility. BMC Pediatr 2019;19(01):13

8 Rahman SU, Canpolat FE, Oncel MY, et al. Multicenter randomized controlled trial of therapeutic hypothermia plus magnesium sulfate versus therapeutic hypothermia plus placebo in the management of term and near-term infants with hypoxic ischemic encephalopathy (The Mag Cool study): a pilot study. J Clin Neonatol 2015;4(03):158

9 El Farargy MS, Soliman NA. A randomized controlled trial on the use of magnesium sulfate and melatonin in neonatal hypoxic ischemic encephalopathy. J Neonatal Perinatal Med 2019;12(04):379-384

10 Bhat MA, Charoo BA, Bhat JI, Ahmad SM, Ali SW, Mufti MU. Magnesium sulfate in severe perinatal asphyxia: a randomized, placebo-controlled trial. Pediatrics 2009;123(05):e764-e769

11 Lingam I, Robertson NJ. Magnesium as a neuroprotective agent: a review of its use in the fetus, term infant with neonatal encephalopathy, and the adult stroke patient. Dev Neurosci 2018;40(01):1-12

12 Zhou KQ, Davidson JO, Bennet L, Gunn AJ. Combination treatments with therapeutic hypothermia for hypoxic-ischemic neuroprotection. Dev Med Child Neurol 2020;62(10):1131-1137

13 Shalak LF, Laptook AR, Velaphi SC, Perlman JM. Amplitude-integrated electroencephalography coupled with an early neurologic examination enhances prediction of term infants at risk for persistent encephalopathy. Pediatrics 2003;111(02):351-357

14 Badr-El Din MM, Abougabal AM, Saad KM, Abdel-Salam HR. Effect of erythropoietin as adjunctive therapy with whole-body cooling for treatment of hypoxic-ischemic encephalopathy in newborns. Alex J Pediatrics 2017;30(02):45-52

15 Azzopardi D, Brocklehurst P, Edwards D, et al; TOBY Study Group. The TOBY Study. Whole body hypothermia for the treatment of perinatal asphyxial encephalopathy: a randomised controlled trial. BMC Pediatr 2008;8(01):17

16 Massaro AN, Murthy K, Zaniletti I, et al. Short-term outcomes after perinatal hypoxic ischemic encephalopathy: a report from the Children's Hospitals Neonatal Consortium HIE focus group. J Perinatol 2015;35(04):290-296

17 Zanelli S, Buck M, Fairchild K. Physiologic and pharmacologic considerations for hypothermia therapy in neonates. J Perinatol 2011;31(06):377-386

18 Valera IT, Vázquez MDC, González MDR, et al. Erythropoietin with hypothermia improves outcomes in neonatal hypoxic ischemic encephalopathy. J Clin Neonatol 2015;4(04):244-249

19 Siegel C, Li J, Liu F, Benashski SE, McCullough LD. miR-23a regulation of X-linked inhibitor of apoptosis (XIAP) contributes to sex differences in the response to cerebral ischemia. Proc Natl Acad Sci U S A 2011;108(28):11662-11667

20 Torbenson VE, Tolcher MC, Nesbitt KM, et al. Intrapartum factors associated with neonatal hypoxic ischemic encephalopathy: a case-controlled study. BMC Pregnancy Childbirth 2017;17(01): 415

21 Hashim N, Naqvi S, Khanam M, Jafry HF. Primiparity as an intrapartum obstetric risk factor. J Pak Med Assoc 2012;62(07):694-698

22 Peebles PJ, Duello TM, Eickhoff JC, McAdams RM. Antenatal and intrapartum risk factors for neonatal hypoxic ischemic encephalopathy. J Perinatol 2020;40(01):63-69

23 Hill A. Current concepts of hypoxic-ischemic cerebral injury in the term newborn. Pediatr Neurol 1991;7(05):317-325

24 Badawi N, Felix JF, Kurinczuk JJ, et al. Cerebral palsy following term newborn encephalopathy: a population-based study. Dev Med Child Neurol 2005;47(05):293-298

25 Dongol S, Singh J, Shrestha S, Shakya A. Clinical profile of birth asphyxia in Dhulikhel Hospital: a retrospective study. J Nepal Paediatr Soc 2010;30(03):141-146

26 Seyal T, Hanif A. Factors related to adverse outcome in asphyxiated babies. Ann of King Edward Med Univ 2009;15(04):180-180

27 Marks K, Shany E, Shelef I, Golan A, Zmora E. Hypothermia: a neuroprotective therapy for neonatal hypoxic ischemic encephalopathy. Isr Med Assoc J 2010;12(08):494-500

28 Jacobs SE, Morley CJ, Inder TE, et al; Infant Cooling Evaluation Collaboration. Whole-body hypothermia for term and near-term newborns with hypoxic-ischemic encephalopathy: a randomized controlled trial. Arch Pediatr Adolesc Med 2011;165(08):692-700

29 Sajid NK, Junaid M, Ahmed S. Therapeutic efficacy of magnesium sulphate on neurological outcome of neonates with severe birth asphyxia. J Univ Med Dent Coll 2018;9(04):1-5

30 Abate BB, Bimerew M, Gebremichael B, et al. Effects of therapeutic hypothermia on death among asphyxiated neonates with hypoxic-ischemic encephalopathy: a systematic review and meta-analysis of randomized control trials. PLoS One 2021;16(02): e0247229

31 Lingam I, Meehan C, Avdic-Belltheus A, et al. Short-term effects of early initiation of magnesium infusion combined with cooling after hypoxia-ischemia in term piglets. Pediatr Res 2019;86(06): 699-708

32 Prakash R. Effect of postnatal magnesium therapy on neonatal seizure in infants with moderate to severe hypoxic ischemic encephalopathy: A post-hoc subgroup analysis. Int J Contemp Pediatrics 2016;3(04):1425-1429

33 Okonkwo IR, Okolo AA. Pediatrics \& neonatal care. Magnesium 2018;30:31

34 Sreenivasa B, Lokeshwari K, Joseph N. Role of magnesium sulphate in management and prevention of short-term complications of birth asphyxia. Sri Lanka J Child Health 2017;46(02): 148-151

35 Aun AE-AK, Hassan HA, Ali WI, Ataky MMA. Transcranial ultrasound in comparison to MRI in evaluation of hypoxic ischemic injury in neonates. Egypt J Hosp Med 2019;74(04):842-852

36 Rutherford M, Biarge MM, Allsop J, Counsell S, Cowan F. MRI of perinatal brain injury. Pediatr Radiol 2010;40(06):819-833

37 Chao CP, Zaleski CG, Patton AC. Neonatal hypoxic-ischemic encephalopathy: multimodality imaging findings. Radiographics 2006;26(Suppl 1):S159-S172

38 Cheong JL, Coleman L, Hunt RW, et al; Infant Cooling Evaluation Collaboration. Prognostic utility of magnetic resonance imaging in neonatal hypoxic-ischemic encephalopathy: substudy of a randomized trial. Arch Pediatr Adolesc Med 2012;166(07): $634-640$ 